\title{
Preservation of the Glomerular Capillary Ultrafiltration Coefficient during Rat Nephrotoxic Serum Nephritis by a Specific Leukotriene $D_{\mathbf{4}}$ Receptor Antagonist
}

\author{
Kamal F. Badr," George F. Schreiner, ${ }^{*}$ Martin Wasserman," and lekuni Ichikawa* \\ *Departments of Medicine and Pediatrics, Vanderbilt University, Nashville, Tennessee 37232; ${ }^{\ddagger}$ Departments of Medicine \\ and Pathology, Washington University, St. Louis, Missouri 63110; and ${ }^{\S}$ Department of Pharmacology, Smith Kline \\ and French Laboratories, Swedeland, Pennsylvania 19479
}

\begin{abstract}
Leukotriene $\mathrm{D}_{\mathbf{4}}$, a potent biologically active lipoxygenase derivative of arachidonic acid in activated leukocytes, depresses the glomerular capillary ultrafiltration coefficient $\left(K_{f}\right)$ and contracts mesangial cells in culture. We therefore investigated its potential role in mediating the reduction in nephron filtration rate seen after induction of experimental nephrotoxic serum (NTS)-induced glomerulonephritis in the rat. Micropuncture measurements were performed in euvolemic MunichWistar rats $2 \mathrm{~h}$ after i.v. administration of $0.8 \mathrm{ml}$ of rabbit serum (group 1, $n=6$ ), $0.8 \mathrm{ml}$ of rabbit anti-rat glomerular basement membrane antibody in the absence (group $2, n=8$ ), or presence (group 3,n=7) of the new highly specific LTD receptor antagonist SK\&F 104353. Quantitation of antibody binding and neutrophil infiltration revealed no differences between groups 2 and 3. Antagonism of endogenous LTD actions, however, was associated with prevention of the NTS-induced fall in SNGFR because of the abrogation of the fall in $K_{f}$ which characterizes this form of experimental glomerulonephritis. Antagonism of endogenous $\mathrm{LTD}_{4}$ had no effect on the NTS-induced increases in pre- and postglomerular arteriolar resistances, and did not affect nephron plasma flow rate or net transcapillary hydraulic pressure difference. The observed highly localized protective action of the $\mathrm{LTD}_{4}$ antagonist on the glomerular capillary points to a possibly major functional role for intraglomerularly released $\mathrm{LTD}_{4}$, likely originating from infiltrating leukocytes, in the pathophysiology of this form of glomerulonephritis.
\end{abstract}

\section{Introduction}

Glomerulonephritis remains a principal cause of acute and chronic renal failure in people, accounting for a substantial proportion of patients afflicted with end-stage renal disease. Despite considerable advances in the understanding of the immunologic mechanisms involved in the initiation and progression of this type of renal injury, less is known regarding the mediators of the functional derangements of glomerular perfusion and filtration observed during the course of this dis-

This work was presented in abstract form at the 19th Annual Meeting of the American Society of Nephrology, Washington, D.C., 7-10 December 1986

Received for publication 25 August 1987 and in revised form 24 November 1987.

J. Clin. Invest.

(c) The American Society for Clinical Investigation, Inc. 0021-9738/88/06/1702/08 \$2.00

Volume 81, June 1988, 1702-1709 orders. The model of nephrotoxic serum (NTS) ${ }^{1}$-induced glomerulonephritis, produced in the rat by the administration of antibody directed against glomerular basement membrane (GBM) antigens (anti-GBM), has proved to be a highly useful tool for evaluating the pathogenesis of glomerulonephritic injury (1). Induction of this form of injury in the Munich-Wistar rat, uniquely endowed with surface glomeruli accessible to direct measurement of glomerular dynamics, has allowed previous investigators to describe the pattern of glomerular microcirculatory derangements underlying the depressed filtration rates observed during the acute (heterologous) $(2,3)$ as well as delayed (autologous) (4) phases of this experimental model. Consensus has emerged from the studies of Blantz and his co-workers $(2,3)$, as well as those of Maddox et al. (4), performed $1-2 \mathrm{~h}$ and 5-16 $\mathrm{d}$ after NTS administration, respectively, that the principal factor accounting for the fall in filtration rates in these animals was a marked reduction in the glomerular capillary ultrafiltration coefficient $\left(K_{f}\right)$. The mediator mechanisms involved in the depression of $K_{f}$, however, remain unknown. Of interest, the sole experimental maneuvers resulting in some amelioration of the fall in $K_{\mathrm{f}}$, as well as prevention of the accompanying proteinuria, were those associated with inhibition of glomerular leukocyte infiltration (5-8).

Recently, we have identified the glomerular microcirculatory actions of a relatively novel class of vasoactive oxygenated derivatives of arachidonic acid, the peptidoleukotrienes (9, 10). These products of the 5-lipoxygenase pathway are now recognized as constituting a major component of leukocytemediated inflammatory and allergic reactions $(11,12)$. In particular, leukotriene $\mathrm{D}_{4}\left(\mathrm{LTD}_{4}\right)$ causes constriction of the efferent arteriole, with a secondary fall in single-nephron plasma flow rate $\left(Q_{\mathrm{A}}\right)$ and rise in glomerular transcapillary hydraulic pressure difference $(\Delta P)$. Despite the latter, single-nephron GFR (SNGFR) is reduced due to a dramatic fall in $K_{f}(10)$. We were struck by the similarity of these responses to exogenously administered $\mathrm{LTD}_{4}$ to the pattern of glomerular hemodynamics observed during the acute phase of NTS-induced injury $(2,3,5)$. In the present study, therefore, we employed a specific $\mathrm{LTD}_{4}$ receptor antagonist recently developed at Smith, Kline and French Laboratories (13-15) to investigate the possibility of a role for this pro-inflammatory white cell product in mediating some of the functional components of this form of acute experimental glomerulonephritis.

\section{Glossary}

\section{$C \quad$ Protein concentration \\ $C_{\mathrm{A}} \quad$ Arterial protein concentration}

i. Abbreviations used in this paper: NTS, nephrotoxic serum; PAH, para-aminohippurate; $\mathrm{SN}$, single nephron. 
$C_{\mathrm{E}} \quad$ Surface efferent arteriolar protein concentration

ERPF Effective renal plasma flow rate

FF Filtration fraction

$K_{\mathrm{f}} \quad$ Ultrafiltration coefficient

$P_{\mathrm{E}} \quad$ Surface efferent arteriolar hydraulic pressure

$P_{\mathrm{GC}} \quad$ Surface glomerular capillary hydraulic pressure

$P_{\mathrm{T}} \quad$ Proximal tubule hydraulic pressure

$\Delta P \quad$ Olomerular capillary hydraulic pressure difference

$\pi \quad$ Colloid osmotic pressure

$Q_{\text {A }} \quad$ Olomerular plasma flow rate

$R_{\mathrm{A}} \quad$ Afferent arteriolar resistance

$R_{\mathrm{E}} \quad$ Efferent arteriolar resistance

RPF Renal plasma flow rate

Upr Urinary protein excretion rate

\section{Methods}

SK\&F 104353 and synthetic LTD $_{4}$ were obtained from Smith, Kline and French Laboratories, Philadelphia, PA. Both were dissolved in $0.9 \% \mathrm{NaCl}$.

\section{Preparation of NTS}

NTS was produced in rabbits by repeated immunization with basement membrane-rich sediment of rat cortex, as previously described (16). The NTS was extensively absorbed with rat erythrocytes and then heated at $56^{\circ} \mathrm{C}$ for $90 \mathrm{~min}$ before use. Nephrotoxicity was determined by the dose required to induce moderate proteinuria (20-50 mg protein/d) in the first $24 \mathrm{~h}$ after intravenous injection. All rats received a standardized dose of $0.8 \mathrm{ml}$. Proteinuria was determined spectrophotometrically by the sulfosalicylic acid method, using albumin as standard.

\section{Quantitation of glomerular antibody binding}

Kidneys from control and nephritic Munich-Wistar rats were evaluated for anti-GBM concentration per glomerulus as follows: $2 \mathrm{~h}$ after the injection of the NTS, the kidneys were thoroughly perfused with $100 \mathrm{ml}$ of phosphate-buffered saline (PBS) preheated to $37^{\circ} \mathrm{C}$. Kidneys were then excised and the cortex dissected from the medulla. Glomeruli were isolated by differential sieving, thereby yielding $>98 \%$ pure glomerular preparations (16). Glomerular counts revealed equal yields from control and nephritic kidneys; $\sim 30,000$ glomeruli per kidney. The glomeruli from each group were placed in a solution of $2 \%$ sodium cholate in PBS, prewarmed to $37^{\circ} \mathrm{C}$, rotated for $1 \mathrm{~h}$ at $37^{\circ} \mathrm{C}$, and then homogenized with a Dounce homogenizer for $4 \mathrm{~min}$. The homogenates were then dialyzed four times against PBS and placed in a sodium acetate buffer, $\mathrm{pH} 2.5$, for $3 \mathrm{~h}$ to elute bound antibody off GBM fragments. The dialysate was microfuged at $10,000 \mathrm{~g}$ for $30 \mathrm{~min}$ at $4^{\circ} \mathrm{C}$. The supernatants and sediments were dialyzed three times against PBS. The concentration of rabbit IgG in both supernatants and sediments was determined by competitive inhibition ELISA according to the following protocol.

Microwell plates (Costar, Cambridge, MA) were coated with rabbit $\gamma$-globulin at a concentration of $500 \mathrm{ng}$ per well in PBS and allowed to remain overnight at $4^{\circ} \mathrm{C}$. The plates were then thoroughly washed for 1 $\mathrm{h}$ in a solution of PBS containing $1 \%$ bovine serum albumin (BSA) with $0.05 \%$ Tween. $50 \mu \mathrm{l}$ of goat anti-rabbit globulin conjugated to horseradish peroxidase in $1 \%$ BSA/PBS at a concentration of $100 \mathrm{ng}$ per well was added together with $50 \mu$ l of either known concentrations of rabbit $\gamma$-globulin, or eluate, or sediment, all in $1 \%$ BSA. After $1 \mathrm{~h}$ at $4^{\circ} \mathrm{C}$, the plates were washed thoroughly, and developed by the addition of $O$-phenylene diamine $\left(0.01 \%\right.$ in distilled water $\left.+0.3 \% \mathrm{H}_{2} \mathrm{O}_{2}\right)$. The reaction was terminated after $30 \mathrm{~min}$ by the addition of $10 \mu \mathrm{l}$ of $1 \mathrm{M}$ $\mathrm{H}_{2} \mathrm{SO}_{4}$ and read at $492 \mathrm{~nm}$ on an automated Titertek microplate reader (Flow Laboratories, McLean, VA). No inhibition of binding was noted at any dilution of the control glomerular homogenates. Comparison of acid eluates and sediment in all groups receiving NTS revealed that $<1 \%$ of the NTS remained bound after acid elution.

\section{Glomerular morphology}

For light microscopy, kidneys were fixed in Karnovsky's fixative. 4- to $6-\mu \mathrm{m}$ paraffin sections were stained with hematoxylin and eosin. Cells possessing nuclei characteristic for polymorphonuclear leukocytes were counted in glomeruli measuring at least $30 \mu \mathrm{m}$ in diameter. 25 glomeruli were counted in each kidney. For electron microscopy, tissues were fixed by immersion in Karnovsky's fixative, and thin sections were stained with uranyl acetate and examined in a Philips EM microscope (Philips Electronic Instruments, Inc., Mahwah, NJ).

\section{Micropuncture studies}

All experiments were performed on anesthetized adult male MunichWistar rats weighing 200-260 $\mathrm{g}$ which were prepared for micropuncture according to protocols described previously (17). In brief, following Inactin anesthesia (Byk, Federal Republic of Germany, $100 \mathrm{mg} / \mathrm{kg}$, i.p), the left femoral artery was catheterized with PE 50 tubing (Clay Adams, Parsippany, NJ) which was used to monitor mean systemic arterial pressure (AP) by means of a pressure transducer (P23Db, Statham Instruments) connected to a direct writing recorder (Gould Instruments Inc., Cleveland, $\mathrm{OH}$ ) and for sampling of blood.

After a tracheostomy, polyethylene catheters were inserted into both jugular veins for infusion of plasma and a solution of inulin $(7.5 \%$ in $0.9 \% \mathrm{NaCl})$, and para-aminohippurate $(\mathrm{PAH})(0.32 \mathrm{mg} / \mathrm{min})$ at 1.2 $\mathrm{ml} / \mathrm{h}$. The left kidney was exposed by a left subcostal incision, separated from the surrounding fat, and suspended on a Lucite holder. The kidney surface was illuminated with a fiberoptic light source and bathed with isotonic $\mathrm{NaCl}$. Homologous rat plasma was administered intravenously at a rate of $10 \mathrm{ml} / \mathrm{kg} \cdot \mathrm{h}$ for $45 \mathrm{~min}$ followed by a reduction in infusion rate to $1.5 \mathrm{ml} / \mathrm{kg} \cdot \mathrm{h}$ for the remainder of the experiment. This protocol of plasma administration has been shown previously to adequately replace surgically-induced plasma losses, thus maintaining euvolemia (17).

In all experiments, micropuncture measurements were started 100-120 min after the administration of either decomplemented rabbit serum or NTS (see below) and carried out as follows: exactly timed (1-2 min) samples of fluid were collected from surface proximal convolutions of each of three to four nephrons for determination of flow rate and inulin concentration and calculation of tubule fluid-to-plasma inulin concentration ratio and SNGFR. Coincident with these tubule fluid collections, two or three samples of femoral arterial blood were obtained in each period for determination of systemic arterial hematocrit and plasma concentration of total protein and inulin. Also, at least three samples of blood were obtained from surface efferent arterioles (star vessels) for determination of immediate postglomerular plasma protein concentration. In addition, two or three samples of urine from the experimental kidney were collected for the determination of flow rate, protein concentration, inulin concentration, and for the calculation of whole-kidney GFR. For these urine collections, indwelling polyethylene ureteral catheters (PE 10) were used.

Time-averaged hydraulic pressures were measured in surface glomerular capillaries $\left(P_{\mathrm{GC}}\right)$, proximal tubules $\left(P_{\mathrm{T}}\right)$, and surface efferent arterioles $\left(P_{\mathrm{E}}\right)$ using a continuous recording, servo-null micropipette transducer system (model 5, Instrumentation for Physiology \& Medicine, San Diego, CA). Micropipettes with outer tip diameters of $\sim 2$ $\mu \mathrm{m}$ and containing $2.0 \mathrm{M} \mathrm{NaCl}$ were used. Hydraulic output from the servo-nulling system was coupled electronically to a second channel of the Gould recorder by means of a pressure transducer. Experiments were performed on the following three groups and two subgroups of rats:

Group I $(n=6)$. In this group of rats, $0.8 \mathrm{ml}$ of decomplemented rabbit serum, the vehicle for NTS, was administered intravenously after cannulation of the jugular veins and a $0.9 \% \mathrm{NaCl}$ solution, serving as vehicle for the $\mathrm{LTD}_{4}$ antagonist, SK\&F 104353, was infused at $1.0 \mathrm{ml} / \mathrm{h}$ for the remainder of the experiment.

Group IA $(n=3)$. In these animals, the effect of administering the LTD $_{4}$ antagonist alone on systemic and renal hemodynamics was tested. Thus, rats received decomplemented rabbit serum in combination with SK\&F 104353 given as an initial bolus of $10 \mathrm{mg} / \mathrm{kg}$ and 
followed by a continuous intravenous infusion of $1 \mathrm{mg} / \mathrm{kg} \cdot \mathrm{h}(1 \mathrm{ml} / \mathrm{h})$ for the remainder of the experiment.

Group II $(n=8)$. In these animals, cannulation of the jugular veins was immediately followed by administration of $0.8 \mathrm{ml}$ of NTS. This was accompanied (in five rats) by initiation of an infusion of $0.9 \%$ $\mathrm{NaCl}$ at $1 \mathrm{ml} / \mathrm{h}$ for the remainder of the experiment, again serving as vehicle control for SK\&F 104353.

Group III $(n=7)$. These rats received NTS as in group II, but were also treated with SK\&F 104353, given as described for group IA.

Group III $A(n=6)$. These animals were prepared for surgery as described above, but, additionally, an electromagnetic flow probe was placed around the left renal artery and connected to a flow meter (Carolina Medical Instruments, Inc., King, NC) whose output was coupled to a third channel of the Gould recorder for continuous monitoring of renal blood flow. Also, a 30-gauge needle was inserted at the take-off of the left renal artery from the abdominal aorta through which an infusion of $0.9 \% \mathrm{NaCl}$ was started at a rate of $0.05 \mathrm{ml} / \mathrm{min}$. In this group of animals, the efficacy of SK\&F 104353 in antagonizing the systemic and renal actions of exogenously administered LTD $_{4}$ was tested. Animals received intrarenal arterial $\mathrm{LTD}_{4}$ in a dose of 1 $\mu \mathrm{g} / \mathrm{kg} \cdot \min$ for $15 \mathrm{~min}$ in the presence $(n=3)$ and absence $(n=3)$ of SK\&F 104353 given as described above prior to $\mathrm{LTD}_{4}$ administration.

\section{Analytical}

Colloid osmotic pressures of plasma entering and leaving glomerular capillaries were estimated from values for protein concentrations $(C)$ in femoral arterial $\left(C_{\mathrm{A}}\right)$ and surface efferent arteriolar $\left(C_{\mathrm{E}}\right)$ blood plasmas. Colloid osmotic pressure $(\pi)$ was calculated according to the equation derived by Deen et al. (18). Values for $C_{\mathrm{A}}$, and thus $\pi_{\mathrm{A}}$, for femoral arterial plasma are taken as representative for values for $C$ and $\pi$ for the afferent end of the glomerular capillary network. These estimates of pre- and postglomerular protein concentration permit calculation of single-nephron filtration fraction (SNFF) and glomerular capillary ultrafiltration coefficient $\left(K_{f}\right)$, as well as resistances of single afferent $\left(R_{\mathrm{A}}\right)$ and efferent $\left(\boldsymbol{R}_{\mathrm{E}}\right)$ arterioles, and initial glomerular plasma flow rate $\left(Q_{\mathrm{A}}\right)$ by using equations described in detail elsewhere (18).

The volume of fluid collected from individual proximal tubules was estimated from the length of the fluid column in a constant bore capillary tube of known internal diameter. The concentration of inulin in tubule fluid was measured by the microfluorescence method of Vurek and Pegram (19). Inulin concentrations in plasma and urine were determined by the macroanthrone method of Führ et al. (20). Protein concentration in efferent arteriolar and femoral arterial blood plasmas were determined using the fluorometric method of Viets et al. (21).

Urinary protein concentration was determined using the Coomassie Brilliant Blue method (22).

\section{Statistical}

The significance of the differences in all the measured parameters among the three principal groups was assessed using two-way analysis of variance. Differences were considered significant at a $P$ value $<0.05$. All values are reported as mean \pm SEM.

\section{Results}

Morphologic examination and neutrophil quantitation. The dose of NTS administered resulted in a mean concentration of $248 \mathrm{pg}$ of antibody bound per glomerulus with a variance of $<20 \%$ among animals. Duplicate animals injected with NTS and killed $2 \mathrm{~h}$ later demonstrated a mean number of glomerular neutrophils equaling $4.1 \pm 0.2$ neutrophils per glomerulus, compared with $0.2 \pm 0.1$ per glomerulus for control animals. Rats receiving NTS in the presence of SK\&F 104353 had significantly more neutrophils, $5.6 \pm 0.4$ per glomerulus, than control nephritic rats. In this last group, glomerular neutro- phils were readily identifiable on electron microscopic analysis as well. Fig. 1 illustrates a glomerular capillary loop in a rat receiving SK\&F 104353 and killed $2 \mathrm{~h}$ after the intravenous injection of NTS. Two polymorphonuclear leukocytes are seen flanking an endothelial cell, which appears partly displaced.

Micropuncture studies. The pattern of systemic, wholekidney, and glomerular microcirculatory hemodynamic parameters observed $2 \mathrm{~h}$ after administration of decomplemented rabbit serum (group I) was similar to that previously established for baseline control values in the euvolemic Munich-Wistar rat (17) and is presented in the top panels of Table I. Additionally, the administration of SK\&F 104353 alone to these rats (group IA) was without effect on any of the parameters measured: GFR, $1.03 \pm 0.05 \mathrm{ml} / \mathrm{min}$; renal plasma flow (RPF) (PAH clearance), $4.1 \pm 0.4 \mathrm{ml} / \mathrm{min}$; SNGFR, $42.1 \pm 1.2$ $\mathrm{nl} / \mathrm{min} ; Q_{\mathrm{A}}, 139 \pm 17 \mathrm{nl} / \mathrm{min}$; SNFF, $0.31 \pm 0.03 ; \Delta P, 34 \pm 1$ $\mathrm{mmHg} ; R_{\mathrm{A}}, 1.87 \pm 0.28$ and $\mathrm{R}_{\mathrm{E}}, 1.19 \pm 0.1710^{10} \mathrm{dyn} \cdot \mathrm{s} \cdot \mathrm{cm}^{-5}$; $K_{\mathrm{f}}, 0.074 \pm 0.014 \mathrm{nl} /(\mathrm{s} \cdot \mathrm{mmHg})$.

Administration of NTS in group II rats was associated with an elevated value of AP ( $121 \pm 4$ vs. $104 \pm 3 \mathrm{mmHg}$ in group I, $P$ $<0.005$ ), a phenomenon not observed in group III animals ( $106 \pm 5 \mathrm{mmHg}, P>0.05$ vs. group I and $P<0.05$ vs. group II). No significant differences in arterial hematocrit were observed among the three groups (See Table I).

Glomerular filtration rate (GFR) as measured by inulin clearance, effective renal plasma flow (ERPF) as measured by PAH clearance, and filtration fraction (FF) were significantly depressed in group II animals as compared with group I controls, the values were $0.61 \pm 0.07$ vs. $1.07 \pm 0.05 \mathrm{ml} / \mathrm{min}, P$ $<0.005 ; 2.74 \pm 0.29$ vs. $3.76 \pm 0.26 \mathrm{ml} / \mathrm{min}, P<0.025$; and $0.22 \pm 0.02$ vs. $0.29 \pm 0.02, P<0.05$, respectively. Treatment with SK\&F 104353 in group III animals was without effect on the NTS-induced fall in RPF $(2.94 \pm 0.22 \mathrm{ml} / \mathrm{min}, P<0.05 \mathrm{vs}$. group I and $P>0.05$ vs. group II). Despite the persistently depressed ERPF, however, the GFR of group III rats was significantly greater than that of group II animals $(0.92 \pm 0.10 \mathrm{vs}$. $0.61 \pm 0.07 \mathrm{ml} / \mathrm{min}, P<0.025$ ) and statistically not different from that of group I controls $(0.92 \pm 0.10 \mathrm{vs}$. $1.07 \pm 0.05 \mathrm{ml} /$ min, $P>0.05$ ). Thus, FF in this group of animals was elevated to 0.32 , a value significantly higher than that of group II rats ( $P$ $<0.005)$. In parallel with these changes in whole-kidney GFR, ERPF, and FF, single-nephron measurements revealed a fall in SNGFR, $Q_{\mathrm{A}}$, and SNFF in group II rats as compared with group I controls $(24.8 \pm 3.9$ vs. $40.4 \pm 1.5 \mathrm{nl} / \mathrm{min}, P<0.005$; $89 \pm 13$ versus $126 \pm 10, P<0.05$; and $0.27 \pm 0.02$ vs. $0.33 \pm 0.02$, $P<0.05$, respectively). Similarly, the presence of the $\mathrm{LTD}_{4}$ receptor antagonist in group III animals was associated with a selective preservation of SNGFR (mean value $40.5 \pm 5.0 \mathrm{nl}$ / min, $P<0.025$ vs. group II and $P>0.05$ vs. group I) while $Q_{\mathrm{A}}$ remained depressed at $93 \pm 11 \mathrm{nl} / \mathrm{min}$, a value significantly less than that of group I animals $(P<0.05)$, but not different from that of group II rats.

Hydraulic pressure measurements in glomerular capillaries, proximal tubules, and efferent arterioles revealed that induction of acute NTS-induced glomerular injury was associated with elevation of $P_{G C}$ ( $58 \pm 2 \mathrm{mmHg}$ in group II vs. $46 \pm 1$ mmHg in group I, $P<0.005$ ), a change not significantly modified by the presence of SK\&F 104353 in group III rats (52 $\mathrm{mmHg}, P>0.05$ vs. groups I and II). No significant differences in $P_{\mathrm{T}}$ were observed among the three groups of animals (13 \pm 1 $\mathrm{mmHg}$ in group $\mathrm{I}, 12 \pm 1 \mathrm{mmHg}$ in group II, and $11 \pm 1 \mathrm{mmHg}$ 


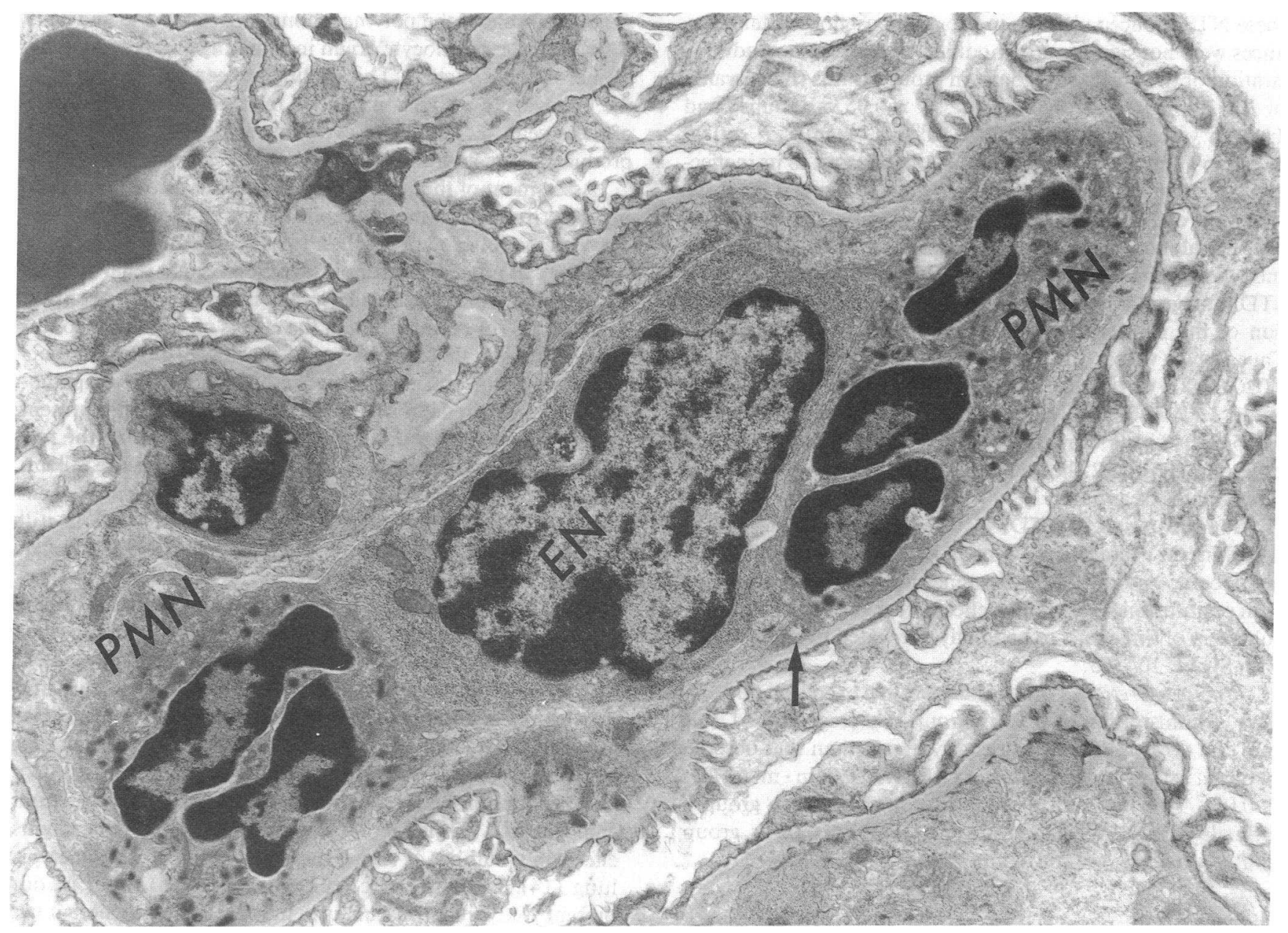

Figure 1. Representative electron micrograph of a glomerulus from a rat which received NTS and was treated with SKF 104353. Note two polymorphonuclear cells $(P M N)$ flanking an endothelial cell $(E N)$ and adhering to the endothelial cell surface. At one point (arrow) the endothelium is lifted off the adjacent basement membrane. The epithelium appears well preserved.

in group III). Thus, the increases in $P_{\mathrm{GC}}$ seen in groups II and III resulted in comparable increases in mean transcapillary hydraulic pressure difference, $\Delta P$, in these two groups of animals. Pressures in surface efferent arterioles, $P_{\mathrm{E}}$, were not significantly different among the three groups. Mean values of superficial cortical pressure measurements in the three groups of animals are summarized in Table $I$.
Calculation of preglomerular and postglomerular arteriolar resistances, $R_{\mathrm{A}}$ and $R_{\mathrm{E}}$, revealed that group II animals were characterized by significant increases in both of these parameters as compared with group I controls $\left(R_{\mathrm{A}}, 2.97 \pm 0.40\right.$ vs. $1.98 \pm 0.1410^{10} \mathrm{dyn} \cdot \mathrm{s} \cdot \mathrm{cm}^{-5}, P<0.05 ; R_{\mathrm{E}}, 2.40 \pm 0.45$ vs. $\left.1.31 \pm 0.1010^{10} \mathrm{dyn} \cdot \mathrm{s} \cdot \mathrm{cm}^{-5}, P<0.025\right)$. Hence, a proportionally greater increase was attained in $R_{\mathrm{E}}$ as compared with $R_{\mathrm{A}}$.

Table I. Summary of Values for Systemic and Single-Nephron Parameters in Groups I, II, and III

\begin{tabular}{|c|c|c|c|c|c|c|c|c|c|c|c|c|c|}
\hline Group & AP & Hct. & GFR & RPF & $\mathrm{FF}$ & SNGFR & $Q_{A}$ & SNFF & $P_{\mathrm{GC}}$ & $\Delta P$ & $R_{\mathrm{A}}$ & $R_{\mathrm{E}}$ & $K_{f}$ \\
\hline & $m m H g$ & vol \% & \multicolumn{2}{|c|}{$\mathrm{ml} / \mathrm{min}$} & \multicolumn{4}{|c|}{$n l / \min$} & \multicolumn{2}{|c|}{$m m H g$} & \multicolumn{2}{|c|}{$10^{10} \mathrm{dyn} \cdot \mathrm{s} \cdot \mathrm{cm}^{-5}$} & $n l /(s \cdot m m H g)$ \\
\hline I & 104 & 46.8 & 1.07 & 3.76 & 0.29 & 40.4 & 126 & 0.33 & 46 & 34 & 1.98 & 1.31 & 0.070 \\
\hline$(n=6)$ & \pm 1 & \pm 1.2 & \pm 0.05 & \pm 0.26 & \pm 0.02 & \pm 1.5 & \pm 10 & \pm 0.02 & \pm 1 & \pm 1 & \pm 0.14 & \pm 0.10 & \pm 0.009 \\
\hline II & $121^{*}$ & 46.1 & $0.61^{*}$ & $2.74^{*}$ & $0.22^{*}$ & $24.8^{*}$ & $89^{*}$ & $0.27^{*}$ & $58^{*}$ & $46^{*}$ & $2.97^{*}$ & $2.40^{*}$ & $0.020^{*}$ \\
\hline$(n=8)$ & \pm 4 & \pm 1.1 & \pm 0.07 & \pm 0.29 & \pm 0.02 & \pm 3.9 & \pm 13 & \pm 0.02 & \pm 2 & \pm 2 & \pm 0.40 & \pm 0.45 & \pm 0.003 \\
\hline III & $106^{\ddagger}$ & 45.7 & $0.92^{\ddagger}$ & $2.94^{*}$ & $0.32^{\ddagger}$ & $40.5^{\ddagger}$ & $93^{*}$ & $0.44^{* \neq}$ & 52 & 41 & 2.63 & $2.47^{*}$ & $0.055^{\ddagger}$ \\
\hline$(n=6)$ & \pm 5 & \pm 0.3 & \pm 0.10 & \pm 0.22 & \pm 0.04 & \pm 5.0 & \pm 11 & \pm 0.02 & \pm 3 & \pm 3 & \pm 0.32 & \pm 0.62 & \pm 0.013 \\
\hline
\end{tabular}

* Statistically different from group I. ${ }^{\ddagger}$ Statistically different from group II. 
These NTS-induced changes in pre- and postglomerular resistances were not significantly modified by concomitant administration of the $\mathrm{LTD}_{4}$ antagonist in group III rats (mean value for $R_{\mathrm{A}}, 2.63 \pm 0.3210^{10} \mathrm{dyn} \cdot \mathrm{s} \cdot \mathrm{cm}^{-5}, P>0.05 \mathrm{vs}$. groups I and II; mean value for $R_{\mathrm{E}}, 2.47 \pm 0.6210^{10} \mathrm{dyn} \cdot \mathrm{s} \cdot \mathrm{cm}^{-5}, P<0.05$ vs. group I and $P>0.05$ vs. group II). In contrast to its ineffectiveness in altering the responses of $Q_{\mathrm{A}}, \Delta P, R_{\mathrm{A}}$, and $R_{\mathrm{E}}$ to the induction of NTS-induced glomerular injury, and in parallel with its salutary effect on the preservation of single-nephron and whole-kidney filtration rates (Table I), the presence of the $\mathrm{LTD}_{4}$ antagonist in group III rats was associated with prevention of the marked fall in $K_{\mathrm{f}}$ observed in group II animals. Thus, while values for this parameter in group II averaged $0.020 \pm 0.003 \mathrm{nl} /(\mathrm{s} \cdot \mathrm{mmHg})$ vs. $0.070 \pm 0.009 \mathrm{nl} /(\mathrm{s} \cdot \mathrm{mmHg})$ in group I $(P<0.005)$, its mean value in group III rats was $0.055 \pm 0.013 \mathrm{nl} /(\mathrm{s} \cdot \mathrm{mmHg})(P>0.05$ vs. group I and $P<0.05$ vs. group II). Fig. 2 shows the individual values for $K_{\mathrm{f}}$ in the three groups of animals.

Administration of $\mathrm{LTD}_{4}$ in three group IIIA animals resulted in, on average, a $10 \mathrm{mmHg}$ rise in AP, a 5 vol\% rise in hematocrit, and a $30 \%$ fall in renal blood flow as compared with preinfusion levels. These effects were shown, in a separate subgroup of three rats, to be totally abrogated by pretreatment with SK\&F 104353.

Protein excretion. Total urinary protein excretion (Upr) $2 \mathrm{~h}$ after administration of NTS in group II averaged $5.2 \pm 1.3 \mu \mathrm{g} /$ $\min \cdot \mathrm{ml} \mathrm{GFR}$, a value significantly higher than that observed in rabbit serum-treated controls $(1.5 \pm 1.1 \mu \mathrm{g} / \mathrm{min} \cdot \mathrm{ml} \mathrm{GFR}, P$ $<0.05)$. This increase in Upr was not observed in group III animals $(\mathrm{Upr}=1.6 \pm 2.2 \mu \mathrm{g} / \mathrm{min} \cdot \mathrm{ml} \mathrm{GFR}, P>0.05$ vs. group I and $P<0.05$ vs. group II).

\section{Discussion}

Mediators of glomerular inflammatory injury have been the subject of extensive research. Examination of the roles of vasoactive peptides and catecholamines (23), the complement cascade $(3,6)$, Hageman factor-related systems (1), oxygen metabolites $(24,25)$, cyclooxygenase products $(26)$, and other mediators (27) of injury has led to the realization that impairment of glomerular filtration and permselectivity functions is the end result of highly complex interactions among these various systems. Despite much controversy regarding the contribution of each of the mediators involved, consensus exists as to

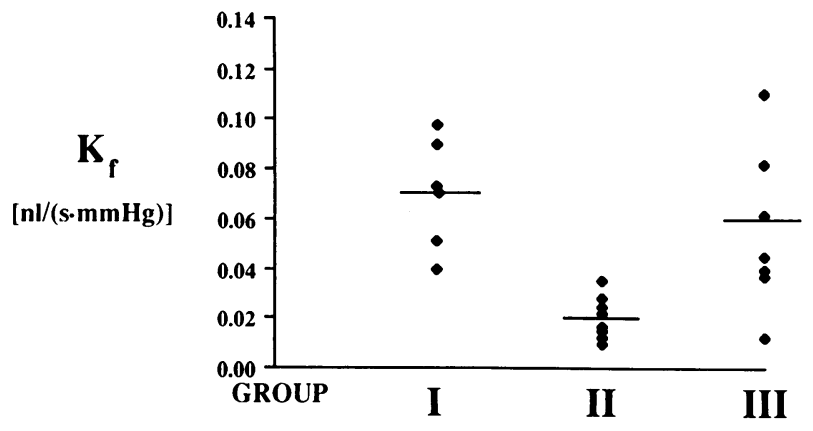

Figure 2. Individual $K_{\mathrm{f}}$ values for all rats studied in groups I, II, and III. Note that, with the exception of one rat, all $K_{\mathrm{f}}$ values in group III animals are greater than those of group II. Horizontal bars indicate means (See Table I). the central role of the polymorphonuclear leukocyte and cells of macrophage/monocyte origin in initiating and perpetuating glomerular dysfunction. This finding has generated interest in the biologically active compounds released during activation of these cells, including the cyclooxygenase and lipoxygenase products of arachidonic acid.

Assessment of the roles played by various eicosanoids during experimental glomerulonephritis has employed two principal methodologic approaches: (a) measurement of endogenous or stimulated eicosanoid synthesis from renal venous effluents or from glomeruli freshly isolated from nephritic kidneys and $(b)$ examination of the effects of selective eicosanoid antagonism through the use of specific enzyme inhibitors and/or receptor antagonists on the histopathologic or pathophysiologic expression of the disease process. In the present studies, we employed the latter approach to examine the role of the peptidyl leukotriene, $\mathrm{LTD}_{4}$, in a model of acute inflammatory glomerular disease. Detection and measurement of endogenous production rates of peptidoleukotrienes is still frought with major methodologic difficulties (28-30). The advantages of the model chosen include the induction of a reproducible, well-characterized, inflammatory reaction within a relatively short time (2-3 h) after administration of NTS, thus allowing for micropuncture measurements, and the relative stability and homogeneity of the glomerular histologic and functional lesions, thus validating the measured singlenephron parameters $(2,31)$. That SK\&F 104353 is indeed a potent and specific receptor antagonist of $\mathrm{LTD}_{4}$ is based on a number of published reports demonstrating that this structural analogue of $\mathrm{LTD}_{4}$ is capable of antagonizing and reversing its effects in a number of tissues including human and guinea pig lung (14), rat basophilic leukemia cells (13), and, in our present study, renal vasculature. In those systems where it has been tested, SK\&F 104353 was found to specifically compete with $\left[{ }^{3} \mathrm{H}\right] \mathrm{LTD}_{4}$ for binding to whole cells (13-15), as well as cell membrane fractions (13-15), and to effect a rightward shift of the dose-response curve of $\mathrm{LTD}_{4}$-mediated hydrolysis of phosphatidylinositol and intracellular calcium mobilization in a highly potent and specific manner (13-15). Of particular relevance to the present observations is our recent demonstration of the presence of specific $\mathrm{LTD}_{4}$ binding sites on cultured rat glomerular mesangial cells, and of the capacity of SK\&F 104353 to competitively inhibit ligand binding to these cells (32).

In the present studies, acute administration of SK\&F 104353 during induction of NTS-induced glomerular injury was without effect on the degree of antibody binding, as well as the number of infiltrating leukocytes in the glomeruli of the affected kidneys. This finding is hardly surprising in view of the notion that $\mathrm{LTD}_{4}$ is devoid of chemotactic activity and the consequences of its release on intrarenal hemodynamics, expected to occur at 2-3 $\mathrm{h}$ after antibody administration, should not affect the initial binding of the antibody to the glomerular basement membrane. Furthermore, recent studies by Yared et al. (33) have demonstrated independence of glomerular antibody binding from the prevailing hemodynamics. The continued demonstration of significant leukocyte infiltration in SK\&F 104353-treated rats is of particular interest since, in the light of the present data, it suggests that the mere physical presence of leukocytes per se may not represent a major pathway of functional impairment. Clearly, however, as evidenced 
by the results of previous studies $(1-6,16,34)$ as well as the present experiments, the biological consequences of leukocyte adherence and activation (such as cytokine release) play a central role in mediating the observed functional derangements (see below).

The capacity of NTS to reduce GFR is a dose-dependent phenomenon. In previous studies by Blantz et al. (3), it was shown that the elevation in $\Delta P$ can counterbalance the reductions in $Q_{\mathrm{A}}$ and $K_{\mathrm{f}}$, thus maintaining GFR, when relatively low doses of antibody are administered. It was our intention in the present study, however, to effect a significant reduction in GFR. Hence, the administered dose of our particular NTS batch was titrated to produce such an effect, and also to result in significant proteinuria at $2 \mathrm{~h}$, as previously reported in this model $(2,3,6,34-36)$. The principal mechanism underlying the fall in GFR and FF was clearly the markedly reduced $K_{\mathrm{f}}$ since the fall in $Q_{\mathrm{A}}$ caused by arteriolar vasoconstriction was offset, to a large degree, by the rise in $\Delta P$. In this regard, the fall in ERPF and $Q_{\mathrm{A}}$ induced by NTS was due to combined increases in both $R_{\mathrm{A}}$ and $R_{\mathrm{E}}$, as previously reported by others (2-4). The proportionately greater rise in postglomerular resistance resulted in the rise in $P_{\mathrm{GC}}$ and $\Delta P$. Antagonism of $\mathrm{LTD}_{4}$ was without significant effect on these NTS-induced changes in arteriolar resistances, and did not improve ERPF, thus indicating that other locally released hormones may mediate this effect. In this regard, Lianos et al. (26) have previously shown, in studies combining measurements of endogenous cyclooxygenase products with whole kidney functional parameters, that the vasoconstrictor eicosanoid, $\mathrm{TxA}_{2}$, plays an important role in the increased renal vascular resistance in this model of glomerular injury. In other studies, Blantz et al. (23), using a specific receptor antagonist, have suggested a role for the alpha-adrenergic system in mediating this effect. In addition, Blantz and co-workers have also shown that complement depletion (3), as well as phentolamine treatment (23), prevented the NTS-induced reduction in $Q_{\mathrm{A}}$, but only partially ameliorated the fall in $K_{\mathrm{f}}$, thus establishing a clear dissociation between the pathophysiologic mechanisms underlying these two abnormalities of glomerular function observed in this model. Of particular interest, these authors related the amelioration of the reduction in $K_{\mathrm{f}}$ in these studies to the exteht of reduction in glomerular leukocyte infiltration, thereby providing the first evidence for linking the fall in $K_{\mathrm{f}}$ to leukocyte-dependent mechanisms. Thus, although exogenous administration of $\mathrm{LTD}_{4}$ to normal rats results in increased postglomerular resistance (as well as decreased $K_{f}$ ) (10), the failure of $\mathrm{LTD}_{4}$ antagonism to modify the observed changes in $R_{\mathrm{A}}$ and $R_{\mathrm{E}}$ during acute NTS-induced glomerular injury supports the above-sited studies as to the involvement of other, non-leukotriene-related systems, in mediating these changes in arteriolar resistances.

In group III animals, the presence of the $\mathrm{LTD}_{4}$ receptor antagonist resulted in prevention of the NTS-induced fall in SNGFR through a marked attenuation of the reduction in $K_{\mathrm{f}}$. This effect appears to indicate that local intraglomerular $\mathrm{LTD}_{4}$ release was responsible for a major portion of the depressed $K_{\mathrm{f}}$. The source of leukotrienes under these circumstances can be postulated as being the activated infiltrating cells of macrophage/monocyte origin, known to be capable of synthesizing lipoxygenase products of arachidonic acid, once the latter is released from cell membrane lipids during cellular stimula- tion. Additionally, resident glomerular cells, bearing $I_{a}$ surface antigen and derived from bone marrow origin, could potentially participate in the release of these compounds during inflammatory processes $(16,37)$. Released leukotrienes would then lead to reductions in $K_{\mathrm{f}}$ either by decreasing capillary permeability or by causing a reduction in glomerular filtering surface area secondary to contraction of mesangial cells. In this regard, $\mathrm{LTD}_{4}$ has been shown to contract cultured glomerular mesangial cells in vitro $(38,39)$ and to cause a fall in $K_{\mathrm{f}}$ and GFR when administered exogenously to normal rats (10). Furthermore, we have recently obtained preliminary evidence documenting the presence of specific $\mathrm{LTD}_{4}$ binding sites on cultured rat mesangial cells and the capacity of $\mathrm{LTD}_{4}$ to stimulate the intracellular generation of inositol triphosphate in these cells (32). It should be noted, however, that the leukotriene-mediated reduction in $K_{\mathrm{f}}$ may be the result of nonmesangial cell-related mechanism(s), such as stimulation of synthesis of other inflammatory mediators or modification of leukocyte-endothelial interactions. Of interest in this regard is the recent demonstration by McIntyre et al. (40) that $\mathrm{LTC}_{4}$ and $\mathrm{LTD}_{4}$ are capable of stimulating endothelial cell synthesis of platelet-activating factor and of increasing neutrophil binding to these cells.

Thus, while the number of neutrophils in group III animals was not diminished as compared to group II, the interactions of these leukocytes with the adjacent endothelium and/or mesangium appears to have been significantly altered by leukotriene antagonism. Fig. 3 schematizes these proposed mechanisms for the actions of $\mathrm{LTD}_{4}$ during NTS-induced glomerulonephritis. As proposed in this figure, antagonism of the biological actions of endogenous leukocyte-derived LT results in reversal of the NTS-induced reduction in $K_{\mathrm{f}}$. Since the fall in $K_{\mathrm{f}}$ was the principal mechanism underlying the reduction in SNGFR (the fall in $Q_{\mathrm{A}}$ being offset by the rise in $\Delta P$ ), antagonism of LTs is associated with restoration of SNGFR. While it is attractive to hypothesize that the mechanism underlying the preservation of $K_{\mathrm{f}}$ in group III rats was prevention of $\mathrm{LTD}_{4^{-}}$ induced mesangial cell contraction, alternate LT-mediated pathways relating to leukocyte-endothelial attachment, endothelial cell injury, or the secondary generation of other autacoids may also mediate the observed reduction in $K_{\mathrm{f}}$.

Of additional interest is the abrogation of NTS-induced proteinuria during $\mathrm{LTD}_{4}$ antagonism by SK\&F 104353 in group III animals. The prevention of proteinuria despite persistently elevated intraglomerular pressure argues against a role for glomerular hemodynamics in the mediation of this abnormality. In previous studies, we and others had demonstrated the capacity of peptidoleukotrienes to increase microvascular permeability to macromolecules and plasma (10-12). In addition, Kreisberg et al. (34) have demonstrated loss of basement membrane-associated anionic charge during the early (heterologous) phase of NTS nephritis. It is possible that similar leukotriene-mediated increases in capillary permeability may be operating in the glomerular microcirculation. Of interest, recent preliminary communications by us and others $(41,42)$ have confirmed the capacity of 5-lipoxygenase inhibitors to abrogate NTS-induced proteinuria, and studies by Mune and others (43) havê demonstrated the presence of a strong correlation between glomerular $\mathrm{LTC}_{4}$ synthesis and the level of proteinuria in this model of glomerular injury.

In summary, these studies present strong evidence suggest- 


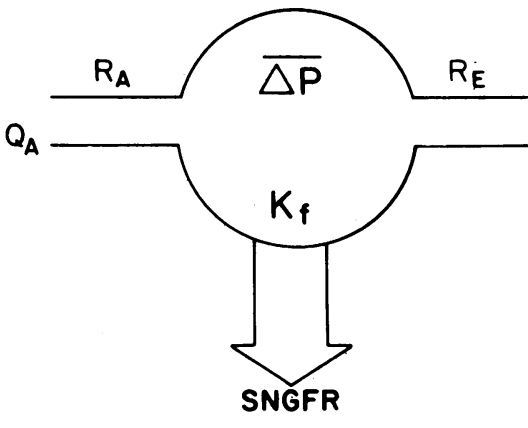

NORMAL

Figure 3. Schematic representation of the changes in glomerular hemodynamics induced by NTS (middle) as compared to the normal (left). Increases in $R_{\mathrm{A}}$ and $R_{\mathrm{E}}$ lead to a fall in $Q_{\mathrm{A}}$ and a rise in $\Delta P$ SNGFR is diminished due mainly to a reduction in $K_{f}$, likely related

ing that $\mathrm{LTD}_{4}$, a highly potent cytokine released from activated leukocytes, plays an important role in mediating the reduction in GFR observed during experimental glomerular inflammatory injury. The effect of $\mathrm{LTD}_{4}$ appears to be highly localized within the glomerulus and is likely expressed through reductions in the glomerular filtering surface area. These observations may provide insight into the mechanisms underlying the tight linkage between leukocyte infiltration and functional impairment which characterizes this form of experimental glomerulonephritis.

\section{Acknowledgments}

This work was supported by grants DK-38667, DK-37868, and AM-36277 from the National Institute of Health.

\section{References}

1. Wilson, C. B., and F. J. Dixon. 1986. Renal response to immunological injury. In The Kidney. B. M. Brenner and F. C. Rector, Jr., editors. W. B. Saunders Co., Philadelphia. 800-890.

2. Blantz, R. C., and C. B. Wilson. 1976. Acute effects of antiglomerular basement membrane antibody on the process of glomerular filtration in the rat. J. Clin. Invest. 58:899-911.

3. Blantz, R. C., B. J. Tucker, and C. B. Wilson. 1977. The acute effect of antiglomerular basement membrane antibody upon glomerular filtration in the rat. The influence of dose and complement depletion. J. Clin. Invest. 59:910-921.

4. Maddox, D. A., C. M. Bennet, W. M. Deen, R. J. Glassock, D. Knutson, T. M. Daugharty, and B. M. Brenner. 1975. Determinants of glomerular filtration in experimental glomerulonephritis in the rat. $J$. Clin. Invest. 55:305-318.

5. Tucker, B. J., L. C. Gushwa, C. B. Wilson, and R. C. Blantz. 1985. Effect of leukocyte depletion on glomerular dynamics during acute glomerular immune injury. Kidney Int. 28:28-35.

6. Cochrane, C. G., E. Unanue, and F. J. Dixon. 1965. A role of polymorphonuclear leukocytes and complement in nephrotoxic nephritis. J. Exp. Med. 122:99-116.

7. Hawkins, D., and C. G. Cochrane. 1968. Glomerular basement membrane change in immunological glomerulonephritis. Immunology. 14:665-671.

8. Henson, P. M. 1972. Pathologic mechanisms in neutrophil-mediated injury. Am. J. Pathol. 68:593-612.

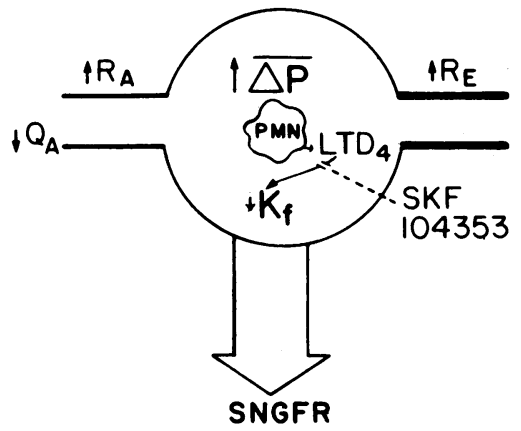

NTS

NTS+SKF 104353

to PMN infiltration and activation with an important intermediary role proposed for the intraglomerular release of $\mathrm{LTD}_{4}$. The glomerulus on the right depicts the modification of these hemodynamic changes in the presence of SK\&F 104353.

9. Badr, K. F., C. Baylis, J. M. Pfeffer, M. A. Pfeffer, R. J. Soberman, R. A. Lewis, K. F. Austen, E. J. Corey, and B. M. Brenner. 1984. Renal and systemic hemodynamic responses to intravenous infusion of leukotriene $\mathrm{C}_{4}$ in the rat. Circ. Res. 54:492-499.

10. Badr, K. F., B. M. Brenner, and I. Ichikawa. 1987. Effects of leukotriene $\mathrm{D}_{4}$ on glomerular dynamics in the rat. Am. J. Physiol. 22:F239-F243.

11. Samuelsson, B. 1983. Leukotrienes: mediators of immediate hypersensitivity reactions and inflammation. Science (Wash. DC). 220:568-575.

12. Lewis, R. A., and K. F. Austen. 1984 . The biologically active leukotrienes. J. Clin. Invest. 73:889-897.

13. Sarau, H. M., S. Mong, J. J. Foley, H-L, Wu, and S. T. Crooke. 1987. Identification and characterization of leukotriene $D_{4}$ receptors and signal transduction processes in rat basophilic leukemia cells. $J$. Biol. Chem. 262:4034-4041.

14. Mong, S., H. L. Wu, J. Miller, R. F. Hall, J. G. Gleason, and S. T. Crooke. 1987. SKF 104353, a high affinity antagonist for human and guinea pig lung leukotriene $\mathrm{D}_{4}$ receptor blocked phosphatidylinositol metabolism and thromboxane synthesis induced by $\mathrm{LTD}_{4} . \mathrm{Mol}$. Pharmacol. 32:223-229.

15. Gleason, J. G., R. F. Hall, C. D. Perchonock, K. F. Erhard, J. S Frazee, T. W. Ku, K. Kondrad, M. E. McCarthy, S. Mong, S. T. Crooke, G. Chi-Rosso, M. A. Wasserman, T. J. Torphy, R. M. Muccitelli, D. W. Hay, S. S. Tucker, and L. Vickery-Clark. 1987. High-affinity leukotriene receptor antagonists: synthesis and pharmacological characterization of 2-hydroxy-3-[(2-carboxyethyl)thio]-3-[2-(8phenyloctyl)phenyl]propanoic acid. J. Med. Chem. 30:959-961.

16. Schreiner, G. F., R. S. Cotran, and E. R. Unanue. 1984. Modulation of Ia and leukocyte common antigen expression in rat glomeruli during the course of glomerulonephritis and aminonucleoside nephrosis. Lab. Invest. 51:524-533.

17. Ichikawa, I., D. A. Maddox, M. G. Cogan, and B. M. Brenner. 1978. Dynamics of glomerular ultrafiltration in euvolemic MunichWistar rats. Renal Physiol. 1:121-131.

18. Deen, W. M., J. L. Troy, C. R. Robertson, and B. M. Brenner. 1973. Dynamics of glomerular ultrafiltration in the rat. IV. Determination of the ultrafiltration coefficient. J. Clin. Invest. 52:1500-1508.

19. Vurek, G. G., and S. E. Pegram. 1966. Fluorometric method for the determination of nanogram quantities of inulin. Anal. Biochem. 16:409-419.

20. Führ, J., J. Kazmarczyk, and C. D. Krüttgen. 1955. Eine einfache colorimetrische Methode zur Inulinbestimmung für NierenClearanceuntersuchungen bei Stoffwechselgesunden und Diabetikern. Klin. Wochenschr. 33:729-730. 
21. Viets, J. W., W. M. Deen, J. L. Troy, and B. M. Brenner. 1978. Determination of serum protein concentration in nanoliter blood samples using fluorescamine or o-phthaldehyde. Anal. Biochem. 88:513521.

22. Bradford, M. M. 1976. A rapid and sensitive method for the quantitation of microgram quantities of protein utilizing the principle of protein-dye binding. Anal. Biochem. 72:248-252.

23. Blantz, R. C., B. J. Tucker, L. C. Gushwa, O. W. Peterson, and C. B. Wilson. 1981. Glomerular immune injury in the rat: the influence of angiotensin II and alpha-adrenergic inhibitors. Kidney Int. 20:452-461.

24. Rehan, A., K. J. Johnson, R. C. Wiggins, R. G. Kunkel, and P. A. Ward. 1984. Evidence for the role of oxygen radicals in acute nephrotoxic nephritis. Lab. Invest. 51:396-403.

25. Webb, D. B., R. Mackenzie, S. N. Zoob, and J. Rees. 1985. Evidence against a role for superoxide ions in the injury of nephrotoxic nephritis in rats. Clin. Sci. 69:687-689.

26. Lianos, E. A., G. A. Andres, and M. J. Dunn. 1983. Glomerular prostaglandin and thromboxane synthesis in rat nephrotoxic serum nephritis. Effects on renal hemodynamics. J. Clin. Invest. 72:14391448.

27. Wilson, C. B., L. C. Gushwa, O. W. Peterson, B. J. Tucker, and R. C. Blantz. 1981. Glomerular immune injury in the rat: effect of antagonists of histamine activity. Kidney Int. 20:628-635.

28. Blair, I. A. 1983. Measurement of eicosanoids by gas chromatography and mass spectrometry. Br. Med. J. 39:223-226.

29. Balazy, M., and R. C. Murphy. 1986. Determination of sulfidopeptide leukotrienes in biological fluid by gas chromatography/mass spectrometry. Anal. Chem. 58:1098-1101.

30. Wynalda, M. A., J. R. Brashler, M. K. Bach, D. R. Morton, and F. A. Fitzpatrick. 1984. Determination of leukotriene $C_{4}$ by radioimmunoassay with a specific antiserum generated from a synthetic hapten mimic. Anal. Chem. 56:1862-1865.

31. Allison, M. E., C. B. Wilson, and C. W. Gottschalk. 1974. Pathophysiology of experimental glomerulonephritis in rats. J. Clin. Invest. 53:1402-1423.

32. Badr, K. F., J. Ebert, R. L. Hoover, S. Mong, and R. C. Harris. 1988. Characterization of leukotriene $\mathrm{D}_{4}$ binding to rat glomerular mesangial cells: demonstration of $\mathrm{LTD}_{4}$-stimulated inositol triphosphate synthesis and ${ }^{3} \mathrm{H}$-thymidine incorporation. Kidney Int. 33:253. (Abstr.)

33. Yared, A., H. Miyazawa, M. L. Purkerson, S. Klahr, D. J.
Salant, and I. Ichikawa. 1988. Effect of diet, age and sex on the renal response to immune injury in the rat. Kidney Int. 33:561-570.

34. Kreisberg, J. I., D. B. Wayne, and M. J. Karnovsky. 1979. Rapid and focal loss of negative charge associated with mononuclear cell infiltration early in nephrotoxic serum nephritis. Kidney Int. 16:290-300.

35. Galaske, R. G., C. A. Baldamus, and H. Stolte. 1978. Plasma protein handling in the rat kidney: mictopuncture experiments in the acute heterologous phase of anti-GBM-nephritis. Pflügers Archiv. Eur. J. Physiol. 375:269-277.

36. Gang, N. F., E. Trachtenberg, J. Allerhand, N. Kalant, and W. Mautner. 1970. Nephrotoxic serum nephritis. III. Correlation of proteinuria, excretion of the glomerular basement membrane-like protein, and changes in the ultrastructure of the glomerular basement membrane as visualized by lanthanum. Lab. Invest. 23:436-441.

37. Schreiner, G. F., J. M. Kiely, R. S. Cotran, and E. R. Unanue. 1981. Characterization of resident glomerular cells expressing la determinant and manifesting restricted interactions with lymphocytes. $J$. Clin. Invest. 68:920-931.

38. Barnett, R., P. Goldwasser, L. A. Scharschmidt, and D. Schlondorff, 1986. Effects of leukotrienes on isolated rat glomeruli and cultured mesangial cells. Am. J. Physiol. 19:F838-F844.

39. Simonson, M. S., and M. J. Dunn. 1986. Leukotriene $C_{4}$ and $\mathrm{D}_{4}$ contract rat glomerular mesangial cells. Kidney Int. 30:524-531.

40. McIntyre, T. M., G. A. Zimmerman, and S. M. Prescott. 1986. Leukotrienes $C_{4}$ and $D_{4}$ stimulate human endothelial cells to synthesize platelet-activating factor and bind neutrophils. Proc. Natl. Acad. Sci. USA. 83:2204-2208.

41. Yared, A., A. Gung, G. Schreiner, I. Ichikawa, and K. F. Badr. 1987. Leukotriene $D_{4}$-induced proteinuria: role in experimental glomerulonephritis. Proceedings of the Xth International Congress of Nephrology, London, July 26-31. 236a. (Abstr.)

42. lino, Y., K. Tachibana, K. Tomita, N. Yoshiyama, S. Tomura, J. Takeuchi, T. Wakabayashi, I. Morita, and S-I Murota. 1987. Effects of 5-lipoxygenase inhibitor (TMK-688) on proteinuria in experimental nephritis. Proceedings of the Xth International Congress of Nephrology, London, July 26-31. 229a. (Abstr.)

43. Mune, S., T. Goto, K. Matoba, S. Yukawa, and H. Nomoto. 1987. Glomerular leukotriene synthesis in rat nephrotoxic serum nephritis. Proceedings of the Xth International Congress of Nephrology, London, July 26-31. 232a. (Abstr.) 